\title{
LA COMPLEJA IDENTIDAD DEL LÉXICO JURÍDICO
}

\author{
Manuel Martí SÁnchez \\ Universidad de Alcalá \\ Grupo TermAH (Grupo de Terminología de Alcalá de Henares) \\ manuel.marti@uah.es
}

\begin{abstract}
Resumen
The terminology of Right is an age long undertaking of the human mind, by means of which it has tried to respond to the necessities, progressively more complex and marked by multiple tensions. This paper has dedicated the first section to the overlaps and differences between categorization and categories of ordinary and special language through the concepts/meanings linguistic opposition. This has been the base to accede to the linguistic performance of specialized knowledge and, from it, to enter the legal one. Within this, legal terminology is already formed a peculiar organization, between what is scientist-technical and institutional, and between the humanities and the axiomatic things. In this characterization it has played a particularly important role to analyse the terms, the semi legal terms based on ordinary words, and their relation with metaphors.
\end{abstract}

\section{Categorización y categorías (ordinaria y terminológica)}

\subsection{Definición y bases de la categorización}

Entendida como el "proceso por el cual entidades distintas son tratadas como equivalentes" (Medin y Aguilar, 2002[1999]: 295), a estas alturas sabe todo el mundo que la categorización es uno de los signos de identidad fundamentales del cognitivismo que en Lingüística se conoce como funcionalista (frente al formalista representado por Chomsky). La categorización, que atraviesa todo el orden mental desde la conciencia primaria a la superior (con la autoconciencia y el lenguaje) (Searle 2000[1997]: 45-55), es una actividad decisiva, desde luego, para el conocimiento humano ${ }^{2}$; y, unida a él, también para las lenguas. El fruto de la categorización, las categorías, son las representaciones mentales que sirven como significado de las expresiones lingüísticas ordinarias (Jackendoff 1990: 11) y también como concepto de las unidades terminológicas. De este modo, para la lingüística que se mueve por

1 Este artículo, revisión de nuestro anterior Martí Sánchez (2004) (escrito en 2002), forma parte de las actividades desarrolladas dentro del Proyecto de Investigación Científica y Desarrollo Tecnológico "Estudio de los Lenguajes Especializados en Español (I). Elaboración y desarrollo de vocabularios científicos y técnicos" (ESLEE), financiado por el Ministerio de Ciencia y Tecnología con la referencia BFF2001-1506.

2 "Un aspecto esencial de la cognición (quizá el esencial) es la capacidad de categorizar: juzgar si una cosa determinada es o no un ejemplo de una categoría determinada" (Jackendoff, 1998 [1987]: 165). 
estos derroteros, el léxico de una lengua "representa una destilación de experiencia humana compartida" (Langacker, 2000: 1), a través de un doble proceso de descontextualización y esquematización (Ibid.: 2), por el que se filtran los rasgos individuales de los elementos.

La categorización no es un proceso individual y aislado, que empieza y concluye sin más en la creación de una categoría. Se halla guiado y condicionado por las otras categorías, organizadas en redes densamente interconectadas, lo que algunos llaman teorías. Tal funcionamiento lo han intuido filósofos como Heidegger:

Si la presentación de algo en el mundo del sujeto es significativa es porque ocurre en el marco de una comprensión determinada, de un ámbito de sentido bajo el cual lo real se presenta de un modo, como tal realidad o siendo asi (Sáez Rueda, 2002: 145)

Y lo han corroborado la psicología cognitivista, con la importancia de los modelos mentales en la organización de los conceptos; $y$, por su parte, la semántica de esta orientación, señalando las bases conceptuales (marcos) de los campos léxicos, que son la estructura en que se integran los contenidos lingüísticos (Allan, 2001: 258, 267; García de Quesada, 2001: 2.4 y 3.). En el universo jurídico, esto es especialmente evidente, puesto que sus términos existen dentro del entramado del Estado legislativo de Derecho (Gascón y García Figueroa, 2003: 17), dentro del cual lógicamente son siempre interpretados ${ }^{3}$.

Además de este contexto categorial, la categorización requiere de los sistemas conceptualizadores y perceptivos comunes ( $\mathrm{y}$ no comunes) a todos los hombres. Tales sistemas suponen unas habilidades cognitivas, que giran en torno a la percepción de semejanzas y entre las que destacan la capacidad de agrupar conjuntos de entidades, la reificación conceptual, el escaneo mental, los esquemas imaginísticos (origen-sendero-meta, continente-contenido, centro-periferia, ligazón, fuerza y equilibrio) y la metáfora (Langacker, 2000: 2-3). De esta última se hablará en estas páginas (cfr., infra, 1.3. y 2.3.).

\subsection{Léxico ordinario y terminológico}

\subsubsection{Las dimensiones sociopragmática y representativa del léxico terminológico}

Postulado ya que el léxico de las lenguas (constituido por morfemas, palabras y combinaciones fijas de estas) es una consecuencia de la capacidad cognoscitiva categorizadora (cfr. Jiménez Ruiz, 2000: 65-66), el siguiente paso son las diferencias entre el léxico ordinario y el propio de las lenguas para fines específicos (ciencia, técnica, instituciones), es decir, el léxico terminológico.

La unidad terminológica, la propia de las lenguas especiales, se diferencia de la unidad léxica ordinaria en su vertiente sociopragmática y en la naturaleza de su representación ${ }^{4}$. Aunque la insistencia en una u otra divida la Teoria General y la Teoria Comunicativa de la Terminología (Cabré, 2000 [1999]: 69-173); entre ambas vertientes distintivas del léxico

3 "Las normas se interpretarán según el sentido propio de sus palabras, en relación con el contexto, los antecedentes históricos y legislativos, y la realidad social del tiempo en que han de ser aplicadas, atendiendo fundamentalmente al espíritu y finalidad de aquéllas" (Código Civil cap. II, art. 3.1).

4 Existen otras posibles marcas del léxico terminológico (sintácticas y presentativas), pero de menor entidad (Allan, 2001: 172). 
terminológico, existe una relación que se encuentra, por ejemplo, en la consideración del discurso y la lengua jurídicos (DLJ) como respuesta adaptativa (cfr., infra, 2.1). Desde la vertiente sociopragmática, las unidades terminológicas se marcan por las actitudes que suscita su reconocimiento social, así como por los fines que guían la comunicación especializada propia de las ciencias, de sus técnicas y de las instituciones (cfr., infra, 1.2.2).

Las diferencias en cuanto a la representación dependen de la diferente categorización. Al examinar esta, se observa a simple vista que las unidades léxicas ordinarias codifican el conocimiento espontáneo, antepredicativo, que se debe a las lenguas ${ }^{5}$; ese que en español ha llevado a distinguir significados como los que expresan los verbos decir, hablar, charlar, susurrar, musitar, bisbisar, insinuar, farfullar, conversar, departir, cotillear, cotorrear... Por el contrario, los términos surgen del conocimiento reflexivo de las cosas (que se identifican, clasifican e interpretan), de ese conocimiento genéricamente científico, que lleva a distinguir, por ejemplo, entre tercerización y terciarización en Economía. Y que exige que su aparición se acompañe de una definición (infra, 2.2.1). Así marca en el Derecho Mercantil es y solo es: "Todo signo susceptible de representación gráfica que sirva para distinguir en el mercado los productos o servicios de una empresa de los de otras" (Ley 17/2001, de 7 de diciembre, de Marcas).

Consecuentemente, con todo ello, las estructuraciones a las que dan lugar las terminologías superan los límites de una lengua ${ }^{6}$ y han de aprenderse, no adquirirse, como si de una segunda lengua se tratara. Los conceptos en Derecho Civil de acogimiento, adopción, tutela... requieren un esfuerzo de aprendizaje consciente; los significados de mentira, trola, embuste, patraña... se adquieren casi completamente por parte del hablante nativo solo hablando y oyendo su lengua.

Como siempre ocurre y actualmente todos admiten, la dicotomía léxico ordinario/terminológico funciona mucho mejor en el mundo de las ideas; en el plano más empírico, los límites son bastante más difusos. Lo son porque los dos conocimientos invocados, el de las lenguas y el científico, están claramente conectados. Ambos necesitan del conocimiento general de las cosas, del conocimiento enciclopédico. Este es la base del conocimiento lingüístico ordinario (Allan, 2001: 101); y la suma del conocimiento enciclopédico más el lingüístico ordinario, la base a su vez del científico. Por eso, la actuación terminológica es siempre sobre y a partir de la lengua ordinaria, sobre la que puede decirse con W. von Humboldt que realiza un acto de violencia (Trabant, 1992: 91-107). Ya nos imaginamos en qué consiste tal violencia, a la que también podría calificarse de esfuerzo. En las lenguas especiales, la realidad no se determina por la visión del mundo, de carácter intuitivo, que se

5

Para Husserl, "el principio de todos los principios" es "que toda intuición en que se da algo originariamente es fundamento de derecho del conocimiento" (Garcia-Baró, 1997: 52).

6 Esto en dos sentidos, las terminologías van más allá del ordenamiento impuesto por la lengua ordinaria, sugiriendo nuevas distinciones y rechazando otras; y las terminologias recurren al trabajo distinguidor realizado en otras lenguas. Prueba esto segundo la presencia creciente en las diversas terminologías científico-técnicas de voces extranjeras. Tal hecho debilita las viejas teorías etnocientíficas, aunque no al punto de negar toda mediación cultural; el carácter circunstancial de lo humano en términos de Ortega siempre está ahí. Sin olvidar esta importante matización, lo que acaba de decirse sobre las terminologias se convierte en algo más profundo con la dicotomía extrema del antropólogo polaco Malinowsky entre el uso salvaje del lenguaje, en el que este es "un modo de actuar, más que [...] un signo de pensamiento" (las cursivas son de Malinowsky), y el uso científico, libre de contexto, "dirigido a quien-pueda-concernir, antes que a un oyente ya vinculado al hablante por un contexto específico que forma parte del significado de las preferencias" (Gellner, 2002[1998]: 235 y 236). 
da en las lenguas a través de los significados; sino por el pensamiento reflexivo, científico, que las lleva a las cosas mismas (Urban, 1979[1939]: 420-421; Trabant, 1992: 97-107)?.

\subsubsection{Los dos aspectos del contenido lingüistico. La denominación de las nuevas realidades}

Llegados a este punto, resulta necesario refinar nuestra teoría del contenido lingüístico (significado y concepto lingüísticos), y así entender mejor las diferencias teóricas léxico ordinario/terminológico. Ya se ha visto que las lenguas por medio de los significados y conceptos imponen una determinada estructuración de la realidad, de modo que cada uno de ellos se corresponde con una entidad surgida de esa realidad estructurada y que, como quería el viejo estructuralismo, se define de modo negativo (es lo que no son las otras con las que se relaciona $)^{8}$. Sin embargo, los significados y conceptos lingüísticos no se agotan con la simple referencia a la realidad representada, no basta con lo que en la tradición fenomenológica se conoce como intencionalidad. Eso conduciría reducirlos en gran medida a la sola dimensión extensional, a la condición de meros índices. Para superar tal reduccionismo hay que considerar la acción de nombrar, el acto de poner un nombre a las cosas; por tanto, la propia denominación.

La categorización que implica el contenido lingüístico exige materializarse en un determinado significante, la cara perceptible del signo. Salvo en las palabras más elementales (niño, perro, madre... $)^{9}$, esta operación denominadora nunca se hace a partir de la nada. Siempre actúa sobre la base de los otros signos preexistentes relacionados con la nueva realidad que quiere nombrarse. Aquí se encuentra la causa instrumental que explica la elección del significante del nuevo signo.

El gran fin de la creación de un nuevo signo, como en seguida aparecerá, es la formulación de nuevas distinciones, porque el progreso en el saber implica un aumento en el número de $\operatorname{estas}^{10}$; pero el fin inmediato, el que ahora importa, no sólo representar una realidad sino

7 Aunque nosotros no nos expresariamos exactamente igual, J. Marías (1973: 13-14) intuye con certeza esta diferencia: "Los términos definidos o estipulados, son en rigor lo contrario de las palabras, que no son resultado de una convención sino que, por el contrario, preexisten a toda situación locuente, de manera que nos encontramos ya con ellas y con su significación". Las diferencias que estamos analizando llevaron a E. Coseriu (1976[1966]: 99) a oponer léxico nomenclator (o terminológico) y estructurado, y a sostener que "las terminologías científicas y técnicas no pertenecen al lenguaje ni, por consiguiente, a las estructuraciones léxicas" (Coseriu, 1976[1966]: 96). Sobre este último extremo, se observa que, reflejo de esta ubicación en el ámbito del conocimiento de las cosas, en la terminología las agrupaciones de unidades lingüísticas no constituyen campos léxicos sino mapas conceptuales. En ellos, las unidades aparecen como mudos cognitivos cuyas relaciones dan lugar a las estructuras que son esos mapas.

8 Además de por estos mares estructuralistas, fácilmente se colige también que nos movemos vagamente dentro de una concepción representacionalista, aunque nos apartamos de lo que es más normal en esta al distinguir entre significado y concepto. Esta práctica es costumbre en Terminología (Cfr. Picht, 2003: 277-279), pero no en la semántica de esta orientación (cfr. Escandell, 2004: 45-48)

9 Aunque constituyen el inicio del proceso denominador, las palabras más elementales no son el punto 0 , tienen también su origen, que apunta a unos signos auditivos (onomatopeyas) y visuales previos (cfr. Bernárdez, 1999: 203-208). Semejante dependencia de unos signos anteriores, aunque no sean verbales, permite que a las palabras elementales también las afecte el segundo aspecto del significado lingüístico que va a establecerse seguidamente. 10 Incrementar las distinciones, hacer más preciso, pues, el léxico es el fin principal de la creación terminológica. Sin embargo, además de él, lo que muestra que las terminologías también son jergas, existe otro gran fin, más difuso, en la creación de nuevos signos: fomentar la solidaridad dentro del grupo, lo que va aparejado a una búsqueda de la separación, de la ocultación elitista (cfr. Allan, 2001: 172). De los fines del léxico terminológico, ya centrados en el jurídico, nos ocuparemos en 2.1. Acerca de la inclinación de las lenguas especiales hacia las jergas, asunto que reaparecerá en 2.2.1 y n. 31 (cfr. Marquant 2002: 181-183). 
también una forma de verla. Recuérdese la afirmación inicial de Langacker del léxico como destilación de la realidad. Tal parcialidad perceptiva, con la que se relacionan fenómenos tan interesantes como las connotaciones o la tendencia a la eliminación de las sinonimias, es el segundo gran aspecto del significado y del concepto lingüísticos. En Economía los términos de prociclidad y recalentamiento a menudo denotan una misma realidad, diferenciándoles la forma de representarla, como reflejan sus significantes. Así, el primero apunta a la existencia en la economía de ciclos que siguen una tendencia que acaba en el alza de los precios; el segundo, focaliza el efecto negativo de esa tendencia que concluye con el sometimiento de la economía a una presión excesiva.

Posteriormente, y como "la costumbre amortigua la sensibilidad" (Kant), tal visión y sus connotaciones tienden a perderse; y si la palabra no experimenta un proceso de revitalización (p.e., a través de un proceso metafórico, en el que caben también las etimologías populares), significados y conceptos se reducen a la simple referencia. Se trata de una vieja ley lingüística. En toda lengua, el afán distinguidor, que persigue la eficacia significativa pero que supone a hablante y oyente un esfuerzo, creativo en el primero y de interpretación en el segundo, choca con la tendencia a la relajación, a la comodidad, que limita y disuelve tantas distinciones. Cuando acaba triunfando esta segunda tendencia, puede decirse, parafraseando a Merleau-Ponty, que la palabra hablante se convierte entonces en hablada, en estado ya de sedimentación y de depósito ${ }^{11}$.

Así pues, en el significado y concepto lingüísticos nos encontramos con dos aspectos, en parte asimilables a la oposición extensión/ intensión. Por un lado, la referencia a una realidad surgida de una estructuración; y, por otro, una determinada manera de percibir esa realidad. Ambos aspectos se recapitulan en E. Husserl (cfr. Martí Sánchez, 2003: 1730) y E. Coseriu. Este último escribió: "el significado, en la denominación primaria absoluta, [...] es objetivación de un contenido subjetivo de la conciencia", y este concierne "al ser de las cosas, es decir, a lo universal de la experiencia individual; dicho de otro modo, a la experiencia como su propia posibilidad infinita" (Coseriu, 1977[1966]: 40. La cursiva en el original).

Detrás de cada aspecto de significados y conceptos, subyace el conocimiento propio de ambos lenguajes, ordinario y terminológico (cfr., supra, 1.1). Por eso, en lo que atañe al segundo, la elección del significante en el léxico terminológico se haya guiado en la medida de lo posible por la racionalidad que le es propia, sin las intermediaciones culturales, subjetivas que dirigen su elección en la lengua ordinaria ${ }^{12}$. De ahí que la condición designativa, intencional de los contenidos transmitidos por las unidades léxicas se manifieste con mucha más fuerza, en las terminologías. Esto da la razón a la idea tan arraigada de que conocer el vocabulario de una lengua especial demanda dominar el saber al que pertenece (cfr., el prólogo de J. C. Sager a Cabré, 1993[1992]. Cfr. Pavel y Nolet, 2002: 7-9):

11 Esta cuestión siempre ha preocupado en relación con los grandes textos jurídicos cargados de ideología (cfr. Martínez García, 1999), y es importante en la creación terminológica fundamental a que dan lugar las nuevas leyes. Surgen nuevos términos porque las palabras cotidianas no valen o dejan de valer, lo que obliga a redefinirlas (infra, 2.2.4.) o a constituir unidades complejas a partir de una palabra común (retención ilegal) (infra, 1.2.3 y 2.2.1.).

12 La racionalidad de la elección terminológica se refuerza por la existencia de diversos organismos (como la ISO), que velan por la normalización terminológica (cfr. Lerat, 1997[1995]: 145-146). 
En realidad, los 'significados' de las terminologías se conocen en la medida en que se conocen las ciencias y las técnicas a las que corresponden y no en la medida en que se conoce la lengua: ellos pertenecen a 'universos de discurso' determinados y no pueden ser definidos sino en relación con estos universos de discurso (Coseriu, 1976[1966]: 98).

\subsubsection{Niveles categoriales según el grado de especificidad}

Lo expuesto sobre el contenido lingüístico y la motivación del significante saca a relucir una distinción entre palabras elementales, las que no parten de un signo lingüístico anterior; y palabras segundas, todas las demás. Tal distinción se enriquece cuando se relaciona con la teoría cognitivista (cfr. Cuenca y Hilferty, 1999: 42-49) de los tres grandes niveles (básico, superordinado y subordinado), según el grado de especificidad de las categorías léxicas. La relación proviene de la correspondencia (relativa) entre los tres niveles y el grado de complejidad formal (esto es, en cuanto al significante) de las palabras.

El léxico ordinario se sitúa mayoritariamente en el nivel básico (el del hablar general, el de las palabras elementales) con las palabras más cortas y fáciles de procesar (niño, perro, cosa, bicho...), de límites poco claros y que son la puerta del acceso natural al mundo. También, aunque en menor medida, el léxico ordinario puebla el nivel superordinado, más específico pero sin traspasar el ámbito difuso del nivel básico. Sus palabras (verdura, animal, pescado...), por su condición de segundas, ya son más complejas estructuralmente.

El léxico terminológico busca el nivel superior, el subordinado, el de las distinciones más precisas. Su ámbito es, frente a los niveles anteriores, bivalente ${ }^{13}$. Estructural y genéticamente, los términos se ajustan (incluidos los préstamos) a dos tipos principales:

- palabras complejas creadas para esa finalidad (compensación flexible, sistemas inteligentes de trading, seguridad semántica, united linked... ${ }^{14}$ ), las más prototípicas, pues la mayor especificidad semántica tiende a la mayor complejidad formal, lo que Langacker (2000: 12) llama complejidad simbólica; y

13 La distinción entre los dos ámbitos la hemos tomado de Del Teso (2002: 36-39), y sirve para enriquecer la oposición entre ambos léxicos. La oposición ámbitos difusos/bivalentes se sitúa en el plano concreto del hablar, no en el abstracto de la lengua; y afecta mucho más a la extensión que a la intensión de los significados. Los límites del significado de las palabras ordinarias son difusos en su uso concreto; entre otras razones, porque el hablar ordinario no requiere de tanta precisión como el terminológico. Un ejemplo de este y del carácter bivalente (discreto) de sus oposiciones lo ofrece la pareja de adjetivos jurídicos sancionador/ sancionatorio. Comentando su falta de sinonimia razona la Real Academia Española (en respuesta a una consulta del Tribunal Constitucional): "Sancionador está formado con el sufijo -dor, que forma adjetivos y sustantivos a partir de verbos, a los que aporta el significado de 'que realiza la acción designada por el verbo base'; así organizador significa 'que organiza', encubridor 'que encubre' y sancionador 'que sanciona'. Asi pues, hablamos de autoridad sancionadora, órgano sancionador, etc. Por el contrario, sancionatorio está formado por el sufijo torio, que forma, a partir de verbos, adjetivos de tipo relacional que significan 'perteneciente o relativo a la acción o efecto designados por el verbo base'; así definitorio significa 'perteneciente o relativo a la definición', recaudatorio 'perteneciente o relativo a la recaudación' y sancionatorio 'perteneciente o relativo a la sanción'. Asi pues, hablamos de factultad sancionatoria, poder sancionatorio, legislación sancionatoria, etc".

14 Con el tiempo, en su uso diario entre los especialistas, las expresiones terminológicas complejas tienden a simplificarse (por comodidad, pero también para diferenciarse de los profanos que empiezan a emplearlas). Así, en la jerga médica, el electrocardiograma es electro; un traumatismo, un trauma; y una radiografia, una placa. No hay dudas de que esas siglas cada vez más frecuentes en los textos de especialidad se deben a un intento por evitar físicamente la pesadez fonológica las expresiones terminológicas complejas, así como al permanente deseo de los especialista de diferenciarse. 
- palabras ya existentes, a menudo ordinarias, adaptadas para este nuevo fin mediante una redefinición, que fortalece la idea de la violencia que ejercen estas lenguas de especialidad sobre la lengua ordinaria (cfr., supra, 1.2.1).

La terminología jurídica ofrece continuos ejemplos de ambos tipos, en la práctica frecuentemente fundidos porque el origen de los complejos léxicos del primer tipo se encuentra muy a menudo en una palabra ya preexistente, que para los juristas constituye el fondo de la unidad poliléxica frente a la última determinación, que constituiría su figura (sucesión contractual, sucesión de empresa, sucesión intestada, sucesión legal, sucesión particular, sucesión por causa de muerte... $)^{15}$. Ya referidos al segundo tipo, el de las palabras redefinidas, podemos decir que los términos jurídicos basados en una sola palabra, casi siempre ordinaria, son muy abundantes (infra, 2.2.4). Así, en Derecho Civil, cosa es "toda entidad material o inmaterial, que tenga una existencia autónoma y pueda ser sometida al poder de las personas como medio para satisfacer una utilidad generalmente económica" (Castán, apud Fernández Martínez coord. 2001). U ocupación es "el modo originario de adquirir el dominio mediante la aprehensión física de una cosa que carece de titular, con la intención de convertirse en dueño de la misma [sic]" (Ortiz Sánchez y Pérez Pino, 2004[2002]).

Estas palabras ordinarias han de redefinirse, pues, para acceder al nivel subordinado y ser aceptadas como términos. En tal proceso la metáfora cumple un importante papel, como vamos a ver seguidamente. La reconversión de palabras ordinarias, por otra parte, muestra que la condición de término es sobre todo funcional. Queremos decir que lo que convierte una palabra ordinaria en término es su función, que sirva para

expresar claramente un significado diseñado, identificado como necesario dentro de un dominio particular por la complejidad y número de conceptos que tiene que distinguir claramente (Kageura, 2002: 14) ${ }^{16}$

Y esta función supone, como ha intentado mostrarse, un diferente proceso categorizador respecto al que se da en la lengua ordinaria.

15 Ejemplos como estos plantean el conocido problema terminológico de los criterios para determinar si se ha
consumado el proceso de lexicalización o (con lo que se tiene una unidad terminológica poliléxica) o si nos move-
mos todavía dentro de la combinación sintagmática, propia de la Sintaxis (cfr. Bevilacqua, 2001; Lorente, 2002).
A nuestro parecer, la base de la distinción se encuentra en que se perciba o no una unidad. Cuanto más fuerte sea
esa percepción, lo que va acompañada del aumento del carácter idiosincrásico de su contenido, en detrimento de
su composicionalidad, con más seguridad se hablará de unidad terminológica en vez de unidades fraseológicas
especializadas. Puede ser de ayuda para entender nuestra posición las pinceladas que sobre la lexicalización
aparecen en Talmy (2000: 23-25), donde se reconoce como un rasgo de la lexicalización que el resultado de una
asociación regular entre un componente semántico y un morfema sea equivalente a un conjunto de morfemas en
una construcción sintáctica. Esto reafirma la importancia de la definición en el reconocimiento de estas unidades
poliléxicas. 16 Esta función puede detallarse más si apelamos a las cuatro conocidas tendencias en el léxico terminológico (B. Spilner, 1992: 43): a) a la más aita precisión posible; b) a evitar la ambigüedad y a buscar la monosemia; c) a la concisión y a la economía lingüística; y d) a la objetividad y a la neutralidad. Tales tendencias están directamente relacionadas con una serie de requisitos que se le han exigido siempre al léxico de la ciencia y de la técnica, y que P. Swiggers (1999: 30-31. Cfr. Nuopponen, 2002: 864-865), con motivo de la terminologia lingüística, sintetiza en los siguientes puntos: sistematicidad, transparencia, adecuación, coherencia y economía. En esta última veía una de las grandes ventajas de la terminología jurídica von Ihering 1994[1858]: 67-68. 


\subsection{Significados descriptivos y metafóricos ${ }^{17}$}

Los dos tipos distinguidos dentro del nivel categorial subordinado propio de las terminologías; el de las unidades poliléxicas creadas para este destino y el de las palabras ya existentes, sometidas a una redefinición responden a procesos categorizadores diferentes en los que la mente humana no actúa igual. En las palabras complejas, en las que encontramos básicamente derivación (librador, desintermediación, encriptación...), composición (agente provocador, infomediarios, cheque electrónico...) y sintagmación (gestión del rendimiento empresarial, dinámicas de evolución competitiva, inteligencia de negocio ${ }^{18} .$. ); estamos ante significados descriptivos, cuyo foco de atención es algún aspecto objetivo de la realidad representada, construidos ordenadamente añadiendo compositivamente progresivamente especificaciones.

En el caso de los significados metafóricos (burbuja financiera, nicho de empleo...), no es la percepción más objetivamente empírica la que actúa ni el razonamiento ordenado en la búsqueda de una progresiva mayor especificidad. Es más bien la imaginación, basada en una intuición inmediata, la que sirve para establecer una relación no convencional entre dos referentes, sobre la base de la analogía y la similaridad, en virtud de la cual una palabra empieza a emplearse para designar una referencia distinta (Goatly, 1997: 108-109). Pensemos en uno de los inicialmente escasos ejemplos de la terminología jurídica, la sumisión del Derecho Procesal, que alude al acuerdo entre las partes en litigio de someterse a un determinado tribunal alterando el fuero territorial ${ }^{19}$.

Una de las aportaciones de los nuevos aires cognitivistas ha sido un replanteamiento de los tropos, especialmente de la metáfora concebida más allá de un medio de hacer más elegante el estilo. El convencimiento de que gran parte del léxico es de origen metafórico y de que estas pueblan la conversación diaria (es un agarrado, es del puño apretado, suelta la mosca, afloja cinco euros, tiene un agujero en la mano, manirroto...) ha llevado a sostener que las metáforas son un medio fundamental, culturalmente motivado (Quinn, 2002[1999]), para conocer lo complejo, lo abstracto por medio de lo más simple y elemental, por lo más próximo a las percepciones físicas. Pero las metáforas no se justifican solo como recurso digamos didáctico, como los equivalentes léxicos de las paremias; a veces, son inevitables dadas las limitaciones de la lengua más directa y literal a la hora de nombrar ciertas realidades $^{20}$. Todas estas razones, empezando por esta última, han sido sentidas por las mismas ciencias para acudir con frecuencia a las metáforas (Martín-Municio, 1992; Martínez-Dueñas, 1993: 73-77).

El esquema significados descriptivos/ significados metafóricos es, y perdón por ser tan reiterativos ante cualquier dicotomía, una simplificación que en cuanto se examina en la

\footnotetext{
17 La distinción procede de Coseriu (1977[1952]).

18 Volvemos a alternar los ejemplos jurídicos con los provenientes de la Nueva Economía. Esta práctica continuará hasta el final de este apartado 1.

19 Este caso es una muestra de ese tipo de metáfora oculta que puebla el léxico jurídico en el que se ha dado uno de los dos procesos metafóricos distinguidos por Goatly (1997: 30): el estrechamiento o ampliación de sentido. Sobre esta cuestión, cfr. 2.3 .

20 Ricoeur ya indicó en 1960 la capacidad reveladora del lenguaje simbólico, indirecto, metafórico, de llegar a donde no puede el lenguaje directo, la descripción empírica, la analítica conceptual (Maceiras, 2002: 229. Cfr. H. Blumenberg, 1992).
} 
realidad empírica se muestra mucho más difusa. Primeramente, porque algo de razón tiene Palmer cuando defiende que el significado (y por extensión el concepto) lingüístico siempre, no sólo el metafórico, depende de la imaginación humana, i.e., de cómo percibimos la realidad:

Las imágenes son interpretaciones particulares de modelos cognitivos [analizables como maneras de organizar experiencias en totalidades estructuradas, p. 52], que están en gran medida estructurados por la cultura (Palmer, 2000[1996]: 147).

Seguidamente, porque metáfora y los procesos creativos de unidades poliléxicas no son excluyentes (Goatly, 1997: 92-106), entre otras cosas, porque en el significado de estos complejos no se explica a menudo por la mera lectura composicional. Esto lo explica muy bien Langacker (2000: 15-16), quien señala que para la gramática cognitiva "las expresiones complejas solo muestran una composicionalidad parcial', que con el tiempo tiende a debilitarse (cfr., supra, n. 15). Compárese la transparencia de accidente de trabajo ('toda lesión corporal que el trabajador sufra con ocasión o por consecuencia de trabajo que ejecute por cuenta ajena') frente a la de acción directa ('acción por la cual los acreedores, en los casos expresamente previstos por la ley, pueden reclamar directamente al deudor de si propio deudor el cumplimiento de la prestación ${ }^{21}$ ), de interpretación mucho más idiosincrásica.

\section{Categorización y categorías jurídicas}

\subsection{El discurso y la lengua jurídicos (DLJ) como respuesta adaptativa}

Como hemos defendido en algún otro lugar con más calma (Martí Sánchez, en prensa), vemos el DLJ como la respuesta a las exigencias que emergen en las diversas situaciones comunicativas (inter e intrapersonales) propias del Derecho, y que constituyen su realidad. Tales exigencias se entienden muy bien acudiendo a los fines de la comunicación jurídica, que representan una modulación específica de los fines generales terminológicos (cfr. n. 10). Entre tales fines de la comunicación jurídica existe una tensión al tratarse de finalidades contrapuestas.

Por un lado, están unos fines racionales y legitimados representados por una finalidad esencial: ordenar (en el doble sentido de establecer un ordenamiento y aplicarlo coercitivamente) la realidad social; y dos fines subsidiarios que limitan los poderes (legislativo y judicial) de los responsables del Derecho: a) convencer/ persuadir/ disuadir, dentro de la argumentación jurídica (tanto en las normas como en las resoluciones judiciales); y b) el control de la expresión mediante la que se crea o se aplica el Derecho ${ }^{22}$. Por otro lado y

21 Las dos definiciones proceden de Ortiz Sánchez y Pérez Pino (2004[2002]).

22 De este control dependen la integridad y la seguridad jurídica (Prieto de Pedro, 1991: 133-135). "La seguridad es el conjunto de medios genéricamente procesales capaz de tornar posible (aunque no inevitable) la justicia a través de la ley" (R.A. Guibourg, 1996: 193). La seguridad contiene dos exigencias fundamentales: la estructural y la funcional. La segunda apunta a la eficacia del derecho; la estructural "exige que la norma haya sido promulgada y publicada, sus términos sean claros, carezca en la práctica de lagunas, tenga en el sistema jurídico una jerarquía fija y respetada, sea anterior a los hechos que regula y garantice la durabilidad de las situaciones creadas bajo su amparo" (Id.). 
frente a ellos, se encuentran unos antifines ocultos pero igualmente vigentes: discriminación positiva de los iniciados y exclusión de la mayoría lega, acciones claramente orientadas al mantenimiento del poder de los primeros, como ha señalado la reflexión crítica de pensadores como Foucault (1996).

Esta respuesta a requerimientos contrapuestos de la que está hablándose es el fruto de una adaptación desarrollada a lo largo de la historia por los distintos actores implicados (Poder legislativo, Administraciones de Justicia y Públicas, mediadores profesionales, científicos del Derecho y ciudadanos en general). Ninguna muestra del DLJ es nunca una respuesta absolutamente individual, al margen de la tradición. Esta última es la fuente, la dotación de la que parte la creación personal de cada jurista (infra, n. 31).

El puzzle del Derecho viene marcado por una complejidad derivada de las múltiples tensiones existentes en su interior. El DLJ reffeja e intenta solucionar permanentemente tales tensiones, que acabamos de focalizar en la lucha entre fines y antifines. Esta posición puede explicarse bastante bien desde la epistemología genética con sus conceptos de autorregulación, equilibrio y equilibración (Piaget, 1978[1975]) ${ }^{23}$. Este último alude a la necesidad de compensar la alteración que las perturbaciones externas y también los desequilibrios internos ocasionan, con una nueva solución equilibradora (Piaget, 1967: 48). Los tres conceptos mencionados son útiles en la explicación del DLJ, y los tres adquieren un nuevo valor cuando se relacionan con la conciencia como causa fundamental del progreso humano ${ }^{24}$. Es esa conciencia la que abriga los numerosos intentos de mejora del DLJ y de los textos administrativos. El último testimonio en nuestra nación que conocemos es el de la Orden del Ministerio de Justicia/3126/2003, de 30 de octubre, por la que se creó una comisión para la Modernización del Lenguaje Jurídico, cuyo objetivo fue:

el establecimiento de una Justicia moderna y abierta a los ciudadanos; esto es, una Justicia transparente, atenta con el justiciable, y, desde luego, comprensible [; a fin]de hacer realidad que las comunicaciones escritas (artículo 5), las vistas y comparecencias (artículo 6) y las propias resoluciones judiciales (artículo 7) resulten inteligibles para el ciudadano no especialista, sin perjuicio de las garantías que derivan de la técnica jurídica.

Creemos que esta perspectiva, desde la que se contempla el DLJ como una respuesta adaptativa a la realidad tensionada del Derecho, permite comprender criticados aspectos del DLJ, y, desde luego, la terminología jurídica y su categorización.

\subsection{La terminología jurídica}

\subsubsection{Términos, semitérminos y palabras generales}

Como corresponde a su condición de lengua de especialidad, la lengua jurídica cuenta con un léxico particular, cuyo conocimiento y uso distingue a sus profesionales. Por supues-

23 Inspirados en Piaget, el DLJ es una estructura, entendida como "un momento en proceso que consiste en una sucesión de estructuraciones y desestructuraciones" (R. García, 1997: 62).

24 Aquí nos ponemos un poco hegelianos. Para Hegel, "la conciencia aparece como permanente superación de sí misma, no impulsada por lo previo e inconsciente, sino motivada por la interiorización de lo otro, por el reconocimiento ético e institucional de los otros, en un proceso de comunicación y expectativa que, al tiempo, supone su propio perfeccionamiento y es causa de la incesante creatividad espiritual" (Maceiras, 2002: 229). 
to, se trata de una realidad muy amplia y heterogénea, en la que las generalizaciones son siempre peligrosas; por lo que cualquier examen mínimamente preciso y comprehensivo de carácter interno demanda atender a criterios como el tipo de texto jurídico ${ }^{25}$ y la rama del Derecho ${ }^{26}$ del que procedan las muestras.

Como no es nuestro objetivo dicho examen, sino la identificación de la terminología jurídica frente a las demás; proseguirá esta visión global tomando como referencia el léxico más representativo, el de las leyes. Hecha esta importante aclaración, puede decirse que al léxico jurídico (LJ) es aplicable, de acuerdo con el grado de prototipicidad terminológica ${ }^{27}$, la clasificación general en términos, semitérminos y palabras comunes convertidas en jergales, esto es, en señas de un grupo social (Nuopponen, 2002: 861; Alcaraz, 2000: 42) (cfr. n. 31).

Los términos jurídicos, stricto sensu, son sus unidades léxicas más representativas: anticresis, avocación, evicción, habeas corpus, impensas, laudo, litisconsorcio, novación, prevaricación, res nullius, usucapión... Sus dos rasgos prototípicos son: a) la especificidad de campo y b) haber sido objeto de una definición terminológica. Esta

presupone que el usuario sabe la intensión del término que se obtiene de las definiciones existentes en los contextos, consultas a especialistas y a través del conocimiento del objeto de estudio [y tiene como] función [...] destacar las características esenciales de la intensión y delimitar la extensión por medio de referencias a otros términos (García de Quesada, 2001)

Además, ha de poseer un carácter estipulativo por la que el objeto que se define se crea gracias a la definición que conlleva el acto también de la denominación.

Habitualmente los estudiosos se refieren a la escasez de ejemplos que dentro de la terminología jurídica cumplen con el primero de los rasgos, la especificidad de campo:

Al contrario de otros lenguajes técnicos, la proporción de palabras usadas de forma exclusiva por el derecho es muy escasa (litispendencia, litisconsorcio, interdicto...); la cuota mayor corresponde a términos del léxico común, e, incluso de otros léxicos técnicos, que el derecho modula semánticamente con acepciones propias (Prieto de Pedro, 1991: 169)

Aunque habrá que volver a algunos extremos de esta cuestión con motivo de la relación LJ y ordinario (cfr., infra, 2.2.4), queremos comentar que quizá no sea tan reducida la nómina de los términos jurídicos, sensu stricto. Están esas unidades terminológicas poliléxicas que, aun con algún componente no específico, el conjunto sí lo es $\mathrm{y}$, desde luego, han sido objeto de definición terminológica. A las muestras ya aparecidas añadimos: legítima global

\footnotetext{
25 La tipología textual jurídica ofrece una estratificación particular, de evidentes repercusiones lingüísticas. Básicamente, están los textos, en primer lugar, mediante los que se manifiestan las normas jurídicas (textos normativos o legales); luego están aquellos donde se aplican dichas normas, dentro de las actividades de la administración de justicia o, en un segundo término, de la administración pública (textos judiciales y jurídico-administrativos); o los negocios jurídicos. En último lugar, estás los textos de los especialistas que hablan del Derecho (textos doctrinales o de la ciencia jurídica).

26 Es interesante la gradación, dentro de las normas legales, respecto a la densidad terminológica que va de la Constitución (grado menor) a las leyes más específicas (grado mayor).

27 También tiene que ver con el distinto origen de los términos, unos préstamos de campos ajenos y otros autóctonos; unos creados por los especialistas y otros tomados del léxico ordinario. Aplicado a los términos latinos gramaticales, cfr. Colombat (1999). De este punto hablamos a continuación.
} 
de descendientes, mesas de contratación, multa coercitiva, negocio fiduciario, obligaciones mancomunadas, pacto de reserva de dominio, quita y espera, rango registral, título al portador, vecindad civil... (cfr., infra, n. 11 y 1.2). Por otro lado, están esas palabras existentes en la lengua ordinaria que en la jurídica han desarrollado una acepción terminológica: inducción, robo, salario, saneamiento, sucesor, subasta, sedición, servidumbre, vacaciones, marcador, tutela, tesoro, tercería...

Estos últimos ejemplos, compartidos con el léxico común (aunque no el sentido con que se toman ${ }^{28}$ ) y algunos remitentes a realidades preexistentes cuyo contenido el Derecho sólo precisa ${ }^{29}$, conducen al grupo de los semitérminos. Aquí también entrarían las unidades léxicas importadas de otros campos disciplinares (cadena productiva, etilómetro, comercio electrónico ${ }^{30}$, sociedad de la información...) y quizá también las expresiones propias del Derecho (instruir, proveer, prescripción, auto...) que no han sido objeto de una definición terminológica.

Estas últimas nos llevan a su vez a las palabras y expresiones ordinarias características del DLJ y que son en gran medida jergales (medida, práctica, regular, vista, inadmisión, dádivas, sala...) (cfr. Alcaraz y Hughes, 2002: 62-63) ${ }^{31}$. Frente a lo que sucede con los términos y semitérminos dominados casi exclusivamente por las expresiones nominales, en este tercer subapartado caben adjetivos (típico), verbos (bastantear), conectores (otrosi)

28 Es dudoso que el especialista cuando emplea estas palabras tenga en la cabeza la polisemia y la homonimia de la voz, esto requiere una conciencia metalingüística que no siempre está operativa (cfr. Talmy, 2000: 5). Al igual que lo que le sucede al usuario del operador de telefonia Amena, que no repara en el adjetivo homónimo; sospechamos que, cuando el jurista habla de tercería en el sentido de 'intervención principal de un tercero en un proceso judicial' (Ortiz Sánchez y Pérez Pino, 2004[2002]), no tiene en la cabeza la actividad celestinesca. Quizá sí la tuvo cuando escuchó de estudiante por primera vez el término con la acepción.

29 Por lo dicho con motivo de la definición estipulativa, no es indiferente para determinar la existencia de un término que este cree su referencia. Esto lo diferenciaría de esos otros casos en los que la actividad terminológica solo precisa (empobreciendo extensionalmente y enriqueciendo intensionalmente) una referencia preeexistente. Aunque el asunto es delicado y la mayoría de los ejemplos son discutibles, hay realidades creadas (relativamente) por el Derecho (retracto, usucapión, titulo al portador, vecindad civil, usufructo, testigo-perito, sustanciación, suplicatorio); pero hay otras preexistentes que se redefinen en este sentido de empobrecimiento y estrechamiento (residencia, robo, salario, vacaciones, uniones de hecho, marcador, tutela, tesoro, sucesor, subasta, sedición).

30 Una idea de la presencia de estos semitérminos importados de la Nueva Economía, la da la definición de comercio electrónico que proporciona la Ley 34/2002, de 11 de julio, de Servicios de la Sociedad de la Información $y$ de Comercio Electrónico: "Cualquier actividad que involucre a empresas que interactúan y hacen negocios por medios electrónicos (...) Se incluye el pedido y pago electrónico y on-line de bienes que se envían por correo u otro servicio de mensajería, asi como el envío on-line de servicios como publicaciones, software e información. Asimismo, se incluyen actividades como diseño e ingeniería cooperativa, marketing, comercio compartido (trade sharing), subastas y servicios postventas"

31 Su presencia avala que la lengua empleada en el Derecho, como cualquier lengua especial, se vea como un uso, como un registro de la lengua histórica (español, francés, inglés...); pero también como una convención que favorece el automatismo y la fluidez, y que se asocia a la competencia comunicativa propia de una comunidad de habla (con su competencia gramatical incluida), de ahí el término sublengua empleado por algunos para hablar de las lenguas de especialidad (Z.Harris et al., 1988). Con estas indicaciones queremos destacar que el dominio del DLJ es un asunto de tradición, de hábitos socialmente reconocidos, a veces, bastante más que del empleo racional de unos términos imprescindibles. Esto evoca el discurso invisible del Derecho, consistente en las convenciones, en las expectativas latentes que gobiernan el modo en que las palabras deben ser utilizadas e interpretadas (cfr. J.B. White, apud Silva, 2001: 28). A este respecto, son muy interesantes los abundantes casos de colocaciones (combinaciones habituales de palabras independientes) que encontramos como manifestación de unas preferencias depuradas con el tiempo: conocer de un pleito, desistir de un pleito, entablar un pleito, ganar un pleito, personarse en un pleito, poner un pleito a alguien, promover un pleito, sobreseer un pleito... (Alcaraz y Hughes, 2002: 99). 
y fraseologismos tan propios como los brocardos (fumum boni iuris; lex posterior derogat priori; prior tempore, potior iure; obiter dicta).

\subsubsection{El lugar de la terminologia del Derecho}

En el universo de las terminologías, la jurídica ocupa un espacio ciertamente particular, diríamos que entre la terminología científico-técnica y la de las instituciones (cfr. Roelcke, 1999: 34-35). Dentro de lo científico-técnico, la terminología jurídica presenta rasgos que la emparentan con las humanidades. Es el caso de la importancia que tienen en ella sus numerosas voces valorativas llenas de ideología, que actúan como los primitivos de las teorías científicas (cfr., infra, 2.2.3.). Estas voces pueden verse como un ejemplo de un doble simbolismo — propio de las ciencias del hombre, y de los mensajes literarios y míticos- que surge cuando los símbolos se cargan de dramatismo (Urban, 1979[1939]: 424-458) ${ }^{32}$. No extraña esta semejanza, dado que Derecho y las ciencias del hombre comparten en una importante proporción un mismo objeto material. Quizá más sorprendente sea la existencia también de alguna coincidencia entre el DLJ, y el discurso y la lengua de las axiomáticas ciencias formales. Al menos, a unos y otros los mueven la misma preocupación por la exactitud, el intento de crear un mundo propio perfecto y la normatividad ${ }^{33}$. Recordemos, además, la existencia de una lógica deóntica, en la que se intenta "expresar el lenguaje imperativo en un lenguaje artificial" (Moreso, 1996: 111).

A la terminología de las instituciones lo aproximan sus enunciados deónticos y realizativos (Jori, 1994: 2096). En relación con estos últimos, el DLJ presenta una evidente dimensión creativa, sus enunciados buscan convertirse siempre en hechos institucionales (Searle, 1980[1969]: 60), sustentados en la condición del orden jurídico de institución humana. De un modo que recuerda lo que ocurre con los mensajes literarios ${ }^{34} \mathrm{y}$, sobre todo, mágicos (Olivercrona, 1992[1962]: 59); el Derecho crea una realidad propia a través del lenguaje ${ }^{35}$.

32 Este hecho guarda relación con los procesos de relexicación observados en el LJ, por los que algunos términos (ejecutoriar, desapoderar...) se cargan de valores irracionales y mágicos, esto es, de connotaciones (Alcaraz y Hughes, 2002: 31). El fin de la relexicación (proporcionar a su léxico un valor especial) conecta con otro fenómeno del DLJ, también muy comentado y criticado. Se trata de la sustitución de las palabras más sencillas por otras más cultas o por perífrasis léxicas, en todos los casos con más peso fonológico (los llamados archisilabos) (cfr. Prieto, 1991: 164 y 190).

33 Para S. Soler (apud Carrió, 1990[1965]: 50), "el comportamiento del Derecho guarda relación con las matemáticas en los dos sentidos: por la forma en que se constituyen los conceptos jurídicos que integran las normas y por la manera en que recíprocamente juegan".

34 Sin que ello obligue a asumir exageraciones posmodernas, que trivializan la seriedad del Derecho y su búsqueda de la verdad; es interesante esa tendencia investigadora que busca los puntos en común entre este y la Literatura. Siguiendo sobre todo a Silva (2001: 66-75), podemos decir —además del mencionado aspecto creativo- que DLJ y Literatura comparten la importancia de la narración de las relaciones humanas, su desvio de la lengua estándar o la necesidad de recurrir a la interpretación. Además, uno y otro, con eslóganes, fórmulas religiosas..., pertenecen a través de sus discursos a los mensajes literales, aquellos que han de reproducirse siempre en sus mismos términos. En lo relativo a la literatura, tal característica es propia sobre todo de la lírica; y en el Derecho, sobre todo de las normas. Esto lo saben muy bien estudiantes y opositores de Derecho.

35 "Esta realidad no es una parte del mundo de los hechos conocidos a través de los sentidos, de la memoria o de la inducción. Es una realidad de un orden superior" (Olivercrona, 1992[1962]: 59). Esto no impide que, desde posiciones nominalistas, se afirme que "todo intento de aprehender esta realidad suprasensible conduce al fracaso" (Id.). 
Referido ya a su aplicación, Kelsen y los realistas americanos defendieron que el juez viene a ser un creador de los hechos que valora (Vernengo, 1996: 255).

\subsubsection{Ideologia, términos valorativos e imprecisiones}

La ubicación del DLJ entre los discursos y lenguas de especialidad ha permitido reparar en una primera característica muy notable: la presencia de términos valorativos, ideológicamente marcados; y, por tanto, con una dosis alta de subjetividad en su interpretación.

En efecto, a la hora de categorizar su mundo (el mundo de las relaciones sociales susceptibles de conflicto), en el Derecho pesan decisivamente los valores ideológicos dominantes en la sociedad (García de Enterría, 1995), en un grado y con una explicitud desconocidos en las terminologías científicas ${ }^{36}$. Observemos el marxismo sociológico (al menos) latente en este fragmento de la Constitución Española:

Art. 129. 1. La ley establecerá las formas de participación de los interesados en la Seguridad Social y en la actividad de los organismos públicos cuya función afecte directamente a la calidad de vida o al bienestar general. 2. Los poderes públicos promoverán eficazmente las diversas formas de participación en la empresa y fomentarán, mediante una legislación adecuada, las sociedades cooperativas. También establecerán los medios que faciliten el acceso de los trabajadores a la propiedad de los medios de producción.

La ideología es el fundamento de ese propósito preceptivo tan característico del DLJ y tan extraño en el discurso científico ${ }^{37}$. Tal finalidad deóntica es una dimensión de sus enunciados, pero a su manera asimismo recae en gran parte de su léxico, sujeta a la división (motivada éticamente) entre lo lícito y lo ilícito. Ideologización más normatividad hace que no resulte extraña la presencia no solo en el DLJ de hechos que se determinan valorativa-

36 Las diferencias ideológicas se comprueban muy bien cuandọ se comparan documentos administrativos pertenecientes a tiempos distintos. Recuérdese la novedad que supuso la Orden Ministerial del 7 de julio de 1986 (BOE, 22-7-1986), por la que se proscribía el uso de fórmulas de tratamiento personal en la Administración Pública (Ministerio de Administraciones Públicas, 1991: 143). El cambio ideológico se encuentra en detalles como que ahora en el Código Penal los delitos relativos a la sexualidad (agresiones y abusos sexuales, acoso sexual, exhibicionismo y provocación sexual, delitos relativos a la prostitución) tienden a englobarse dentro de los delitos contra la libertad sexual. El común denominador de todos ellos, de acuerdo con la norma básica que los sustenta, es la violencia o intimidación, la ausencia de consentimiento. El anterior fundamento moral (la defensa de la virginidad y la castidad femeninas) ha desaparecido por completo.

37 Esto no supone que el mundo del Derecho, cuya creación se debe a personas (a menudo científicos juristas) imbuidos del cientifismo moderno, renuncie en esa tarea de categorizar el mundo de las relaciones humanas a la información que le prestan las distintas ciencias positivas que se encargan de las diversas parcelas, incluidas como muestran recientes leyes sobre tecnologías de la información y el conocimiento, la Nueva Economía o la bioingeniería. Otro ejemplo de la Ley 34/2002, de 11 de julio, de servicios de la sociedad de la información y de comercio electrónico: "Estos servicios son ofrecidos por los operadores de telecomunicaciones, los proveedores de acceso a Internet, los portales, los motores de búsqueda o cualquier otro sujeto que disponga de un sitio en Internet a través del que realice alguna de las actividades indicadas, incluido el comercio electrónico". Un fenómeno que obliga a la reflexión, y muestra de la complejidad siempre de estos, es la insatisfacción de los juristas ante la imprecisión de algunos de los términos científicos tomados de otras áreas, donde no pueda haber tanta exactitud como exige el Derecho. Ya que se ha hablado de bioingeniería, esto es lo que sucede con el sintagma preembriones no viables, tal y como aparece en la Ley 35/1988, de 11 de noviembre, sobre técnicas de reproducción asistida (Gascón y Garcia Figueroa, 2003: 113). 
mente ${ }^{38}$, sino de términos per se valorativos (diligente padre de familia, precio justo, alarma social, imprudencia simple, litigante temerario, abuso de derecho, diligencias para mejor proveer, protección del menor, maltratos fisicos...), muy especialmente los conocidos como conceptos jurídicos indeterminados, conceptos válvula o estándares jurídicos: igualdad, justicia, libertad... (Cfr. Ruiz Manero, 1996: 151).

A este respecto, conviene reparar en la abundancia en el mundo legal de términos que encierran conceptos que se presentan descriptivamente, pero en los que late una valoración, cuya subjetividad no se amortigua del todo. Son los términos cuasidescriptivos de Wroblewski ${ }^{39}$. La definición de alevosía puede darnos una idea de lo que queremos decir. La alevosía se da

cuando el culpable comete cualquiera de los delitos contra las personas empleando en la ejecución medios, modos o formas que tiendan directa o especialmente a asegurarla, sin el riesgo que para su persona pudiera proceder de la defensa por parte del ofendido (Código Penal, Lib. I, Título I, art. 22)

Este rasgo distintivo del DLJ del que está hablándose tiene sus repercusiones, ya que la existencia de tal vocabulario ética e ideológicamente marcado es el origen de muchas de las tradicionales deficiencias achacadas al DLJ. Un vocabulario no guiado en sus fundamentos por un afán objetivo distinguidor, sino por motivaciones de orden más subjetivo e irracional, es caldo de cultivo para las sinonimias (frecuentes en esas parejas o tripletes de términos coordinados) y polisemias observadas a menudo en el discurso jurídico (Iturralde, 1989: 49; Etxebarría, 1997: 358; Alcaraz y Hughes, 2002: 22). Lógicamente, también lo es de la presencia en los discursos jurídicos de ambigüedades $^{40}$ y vaguedades (Moreso, 1996: 108-111; Gascón y García Figueroa, 2003: 112-116). La vaguedad, que se produce cuando no pueden precisarse los objetos recubiertos por un determinado término, es lo que ocurre con voces jurídicas como nocturnidad, habitualmente, armado, penosidad, prodigalidad... Estas voces representan lo que en la psicología cognitiva se conoce como categorías prototípicas ${ }^{41}$, de límites difusos y en intersección con otras categorías. Para Engisch, "la mayoría de los conceptos jurídicos son, al menos parcialmente, indeterminados" (apud Baldinger, 1977[1970]: 73). Todo ello muy normal en el léxico ordinario; pero sorprendente en el terminológico.

Evidentemente, estos ejemplos alejan a la terminología jurídica del ideal de objetividad y de control por métodos públicos propio de la lengua de la ciencia; y, por tanto, de las

38 "Las valoraciones que orientan las decisiones judiciales no son únicamente aquellas preferencias, muy genéricas, que pueden resultar de alguna idea de la justicia o de otros valores un tanto abstractos, sino de las preferencias concretas circunstanciales que llevan al juez a aceptar alguna versión sobre los hechos del caso, descartando otras, y a invocar ciertas normas, poniendo de lado la aplicación de otras también válidas" (Vernengo, 1996: 258). Esta última idea nos hace pensar en las verdades silenciadas del Derecho (Silva, 2001: 45-47).

39 "La definición de estos términos es prima facie descriptiva, pero su estructura profunda revela un carácter valorativo" (Iturralde Sesma, 1989: 48).

40 Una muestra entre muchas de ambigüedad se refleja en esta descuidada redacción: "Las administraciones públicas sólo podrán contraer obligaciones y realizar gastos de acuerdo con las leyes" (Constitución Española, art. 133. 4. La cursiva es nuestra M.M.). En una lectura literal no queda claro lo que cae bajo el ámbito de la restricción "de acuerdo con las leyes". Otros ejemplos: Gascón y García Figueroa (2003: 114).

41 En ellas se basa la famosa cita de Hart: "[Hay casos centrales claros] y otros en los que hay tantas razones para afirmar como para negar lo que se aplica" (apud Moreso, 1996: 109). 
exigencias de seguridad e integridad ${ }^{42}$. Así las cosas, las frecuentes críticas vertidas sobre el DLJ parecen justificadas. Sin embargo, un examen más atento conduce a una matización de semejantes ataques. Reiterando que el DLJ es una respuesta a las múltiples tensiones radicadas en el Derecho (cfr., supra, 2.1) ) $^{43}$ podemos entender que existan términos ideológicos, valorativos y, por tanto, con una dosis importante de vaguedad. Así es el DLJ, porque así es el Derecho. Además, estos términos no son solo una deficiencia sin más (lo que no niega que siempre puedan mejorarse), gracias a ellos, los sistemas jurídicos se flexibilizan, son más equitativos, pues permiten a los que los aplican un "margen de discrecionalidad" (Iturralde, 1989: 48; Peralta, 1994: 81-96).

Este conjunto de imperfecciones comentadas del DLJ suscitan, por otra parte, una pequeña reflexión filosófica. El DLJ se opone, a su manera, a la condena al silencio, formulada por Wittgenstein en el Tractatus, de toda ética (Muguerza, 1992: 137). Es bien sabido que para el filósofo austriaco sólo pueden decirse las proposiciones de la ciencia natural, de lo demás hay que callar. El DLJ desoye tan inhumana prohibición por razones prácticas y de sentido común que reclaman la necesidad del Derecho. Pero no solo por eso. El DLJ se salva de la condena wittgenstiana, aun sin una oposición directa a esta, porque, como se ha indicado con motivo de sus enunciados realizativos, su mundo es un mundo autónomo, propio; constituido por hechos establecidos por la creación jurídica, hechos que se convierten en normas cuando se trasladan al mundo normal, cotidiano.

\subsubsection{Tradicionalidad (estabilidad y dependencia de la lengua ordinaria)}

Junto a esta relevante presencia de términos valorativos ideológicamente marcados, existen otras propiedades de la terminología jurídica en las que los estudiosos también han reparado. Se trata de su estabilidad y su dependencia de la lengua ordinaria, que la definen como una terminología muy tradicional:

El léxico del lenguaje jurídico-administrativo es muy estable, a diferencia de lo que ocurre con otros lenguajes, como el político o el científico, que crean constantemente vocablos nuevos: se trata de un léxico culto, ritual y con escaso margen de variación (E. de Miguel, 2000: 98)

\footnotetext{
42 "La seguridad es el conjunto de medios genéricamente procesales capaz de tornar posible (aunque no inevitable) la justicia a través de la ley" (R.A. Guibourg, 1996: 193). La seguridad contiene dos exigencias fundamentales: la estructural y la funcional. La segunda apunta a la eficacia del derecho; la estructural "exige que la norma haya sido promulgada y publicada, sus términos sean claros, carezca en la práctica de lagunas, tenga en el sistema jurídico una jerarquia fija y respetada, sea anterior a los hechos que regula y garantice la durabilidad de las situaciones creadas bajo su amparo" (Ibid.).

43 Como las que existen entre la aspiración a la justicia perfecta y las limitaciones impuestas por la realidad (lengua ordinaria, cognición humana ...), entre fines legitimados y contrafines ocultos (cfr., supra, 2.1), entre innovación y tradición, entre los requisitos de la comunicación especializada y la necesidad de que las normas sean conocidas por todos, entre la necesidad de ordenar la realidad social y la inestabilidad y complejidad de esta, entre la cooperación y el ineludible conflicto entre los distintos actores, entre el Derecho como realidad que debe aplicarse en la vida práctica y el Derecho como materia para teorizar ... Muy características son las tensiones que surgen a partir de los llamados casos dificiles, en los que se enfrentan Justicia y Equidad, Justicia y el Derecho como sistema conceptual y de reglas de interpretación y aplicación; entre Libertad, Igualdad y Justicia como ideales del Derecho...
} 
Tales propiedades se observan muy bien cuando se vuelve a la constitución del léxico del Derecho (cfr. supra, 1.2.3 y 2.2.1; Alcaraz y Hughes, 2002: 66-71). Gran parte de él lo forman cultismos y arcaísmos (accesión, acrecimiento, coacciones, dadivas, caminos ${ }^{44}$, morada, preterición, requerimiento, resarcimiento, rescisión residencia, resolución, supérstite...) y agrupaciones complejas de dos o más términos, ordenadas internamente de modo jerárquico y donde reaparecen estos cultismos y arcaísmos (caso fortuito, repudiación de herencia...). Además, se da una significativa presencia de latinismos (delicti commissi, fideicomiso, lex loci, litis...), parte de una rudimentaria lingua franca usada por los juristas de muchos países.

Que muchos de los términos y semitérminos jurídicos sean o contengan al menos originariamente palabras ordinarias, mayoritariamente cultismos y arcaísmos es un hecho sumamente significativo. Esto es posible, claro está, porque tales palabras han experimentado una redefinición (supra, 2.2.1) que les ha posibilitado acceder al nivel categorial subordinado (supra, 1.2.3). En cuanto a las razones de este hecho, sus dos motivos fundamentales se encuentran en la obligación del DLJ, al menos en su nivel más fundamental, de ser comprensible para todos, pues a todos afecta; y en lo que podemos llamar la ontología jurídica. Como venimos apuntando, el Derecho crea un mundo propio, pero sobre la base del mundo socialmente admitido, el de las personas normales, que ha de ordenar. $\mathrm{Y}$ este mundo es el ámbito propio de la lengua ordinaria.

\subsection{La metáfora en el DLJ}

En 1.3 nos referimos a la importancia cognitiva de las metáforas en la categorización, y a cómo la ciencia no las rehúye (supra, 1.3). Cuando hubo que concretar la presencia de metáforas en la terminología jurídica, se aludió a la escasez de éstas aunque interpretáramos un término jurídico sumisión como metáfora de acuerdo con el segundo de los tipos distinguido por Goatly (supra, n. 19).

Tenemos, pues, dos datos: la escasez de metáforas jurídicas, pero la posibilidad de incrementar estas con una concepción digamos amplia de la metáfora. Esto es posible, siempre y cuando se salvaguarde la exigencia fundamental de que

el acto no convencional de referencia o coligamiento [propio de la metáfora] sea comprendido sobre la base de la similaridad y la analogía que envuelve al menos lo siguiente: la unidad del referente convencional y la unidad del referente no convencional (Goatly, 1997: 109)

A pesar de que en la práctica tal relación no opere a menudo en la mente del usuario de un término jurídico susceptible de tomarse como metáfora (supra, n. 28), es posible en abstracto tomar como metáforas los términos y semitérminos constituidos total o parcialmente por palabras ordinarias ${ }^{45}$. Examinemos un nuevo ejemplo: tradición es el 'elemento, junto al título, de la adquisición de dominio y derechos reales'. Tradición puede ser la posesión 
de las llaves de una vivienda como símbolo de su legítimo dominio (Ortiz Sánchez y Pérez Pino, 2004[2002]). Esta idea nuestra de que la redefinición de las palabras ordinarias es el medio por el que entran las metáforas en el DLJ se fortalece con su función de facilitar el conocimiento de una realidad abstracta por medio de una realidad más concreta (supra, 1.3).

Naturalmente, esta postura que está defendiéndose no puede oscurecer el primero de los datos: la impresión que produce el LJ es la de ser parco en metáforas. En el DLJ no existen metáforas tan vivas y activas como las económicas crédito blando, cuello de botella en la cadena de suministro, desaceleración económica, maquillaje (contable)..., en las que la imaginación es decisiva. La explicación de todo ello la encontramos en que, con las excepciones explicables por el género discursivo y/o la naturaleza de su autor, el DLJ es muy poco creativo; en él hay poco espacio para la libertad imaginativa e, indudablemente, ninguno para ese humor que se permiten a veces los científicos. Se ha hablado de que el DLJ representa la negación del estilo (E. de Miguel, 2000: 94), lo que no es precisamente amigo de la metáfora en este sentido fuerte.

\section{Final}

Llevamos tiempo estudiando la terminología jurídica desde una óptica digamos funcionalista, construida sobre la idea de la realidad jurídica como tensión y del DLJ como su respuesta, una respuesta tradicional pero en continuo cambio por la acción individual y la propia dinamicidad de esa realidad. Desde tal fundamento, se ha ofrecido una aproximación desde lo más general (la categorización y las categorías ordinarias y especiales) a lo más particular del LJ. Llegados a este extremo, nuestro foco de interés ha sido el examen de sus principales lugares comunes: la preponderancia en él de palabras ordinarias redefinidas que tienden a cargarse de valores ideológicos y que son razón mediata de su fuerte tradicionalidad. Dicho análisis ha concluido examinándose el supuesto carácter escasamente metafórico del LJ, que, sin rechazarse del todo, debe claramente matizarse de la mano de una definición más comprehensiva de metáfora.

\section{Referencias bibliográficas}

Alcaraz Varó, E. (2000): El inglés profesional y académico. Madrid, Alianza.

Alcaraz Varó, E. y B. Hughes (2002): El español jurídico. Barcelona, Ariel.

Allan, K. (2001): Natural Language Semantics. Oxford/Malden, USA, Blakwell.

Atienza, M. (1996): “Argumentación jurídica”. En Garzón Valdés, E. y F. J. Laporta (eds.) (1996), págs. 231-238.

Baldinger, K. (1977 [1970]): "El lenguaje jurídico". En Teoria semántica. Hacia una semántica moderna. Madrid, Alcalá, págs. 62-78.

Bernárdez, E. (1999): ¿Qué son las lenguas? Madrid, Alianza.

Bevilacqua, Cl. (2001): "Unidades fraseológicas especializadas (UFE): elementos para su identificación y descripción". En La terminologia cientifico-técnica: reconocimiento, análisis y extracción de información formal y semántica (DGES PB96-0293). Barcelona, IULA, págs. 113-141.

Blumenberg, H. (1992): "Aproximación a una teoría de la inconceptualidad", Revista de Occidente, 132, págs. 5-24.

Cabré, M.T. (1993 [1992]): La terminología. Trad. española de C. Tebé. Barcelona, Ampuries. 
Cabré, M. T. (2000 [1999]): La terminología Representación y comunicación. Barcelona, IULA (Universitat Pompeu Fabra).

Carrió, G. R. (1990[1965]): Notas sobre derecho y lenguaje. B. Aires, Abeledo/Perrot.

Coseriu, E. (1976[1966]): “Introducción al estudio estructural del léxico". En Principios de semántica estructural. Versión española de M. Martínez Hernández (revisada por el autor). Madrid, Gredos, págs. 87-142.

Coseriu, E. (1977[1952]): "La creación metafórica y el lenguaje". En El hombre y su lenguaje. Estudios de teoría y metodología lingüística. Madrid, Gredos, cap. III.

Cuenca, M.J. y J. Hilferty (1999): Introducción a la lingüistica cognitiva. Barcelona, Ariel.

Escandell, $\mathrm{M}^{\mathrm{a}}$ V. (2004): Fundamentos de semántica composicional. Barcelona, Ariel.

Etxebarría Aróstegui, M. (1997): "El lenguaje jurídico-administrativo: propuestas para su modernización y normalización”. Revista Española de Lingüística, 27.2., págs. 341-380.

Fernández Martínez, J. M. (coord.) (2001): Diccionario jurídico. Elcano, Aranzadi.

Foucault, M. (1996): La verdad y las formas juridicas. Trad. esp. de E. Lynch. Barcelona, Gedisa.

García, R. (1997): "Análisis constructivista de los conceptos básicos de la ciencia". En Id. (coord. General). Epistemología genética y la ciencia contemporánea. Homenaje a Jean Piaget en su centenario. Barcelona, Gedisa.

García de Enterría, E. (1995): La lengua de los derechos. Madrid, Alianza.

García de Quesada, M. (2001): Estructura definicional terminográfica en el subdominio de la oncología clínica. Estudios de Lingüística Española, 14: http://elies.rediris.es/elies14/index.html (01-04-2004).

García-Baró, M. (1997): Husserl (1859-1938). Madrid, Ediciones del Orto.

Gascón, M. y Alfonso J. García Figueroa (2003): La Argumentación en el Derecho. Algunas cuestiones fundamentales. Lima, Palestra.

Garzón Valdés, E. y F. J. Laporta (eds.) (1996): El derecho y la justicia. Madrid, CSIC/ BOE/ Trotta (Enciclopedia Iberoamericana de Filosofía, 11).

Gellner, E. (2002[1998]): Lenguaje y soledad. Wittgenstein, Malinowsky y el dilema de los Habsburgo. Traducción de C. Ors. Madrid, Síntesis.

Goatly, A. (1997): The Language of Metaphors. Londres/ N. York, Routledge.

Guerrero Ramos, G. y M. F. Pérez Lagos (coord.) (2002): Panorama actual de la terminología. Granada, Comares.

Guibourg, R.A. (1996): "Fuentes del Derecho". En Garzón Valdés. E. y F. J. Laporta (eds.) (1996), págs. 177-197.

Harris, Z. et al.(1988): The Form of Information in Science. Dordrecht/ Boston, Kluwer Academic Press.

Ihering, R. von. (1994[1858]): "Teoría de la técnica jurídica". En Casanovas, P. y J. J. Moreso (eds.): El ámbito de lo jurídico. Traducción de S. Sanjosé. Barcelona: Crítica, págs. 60-108.

Iturralde Sesma, V. (1989): Lenguaje legal y sistema jurídico. Cuestiones relativas a la aplicación de la ley. Madrid, Tecnos.

Jackendoff, R. (1998[1987]): La conciencia y la mente computacional. Trad. de A.Ardid Gumiel. Madrid, Visor.

Jiménez Ruiz, J. L. (2000): Epistemología del lenguaje. Alicante, Universidad de Alicante.

Jori, M. (1994): "Legal Performatives". En Asher, R.E. y J.M.Y. Simpson (eds.). The Encyclopaedia of Language and Linguistics, 4. Oxford-N. York, Pergamon, págs. 2092-2097.

Kageura, K. (2002): The Dynamics of Terminology. A descriptive theory of term formation and terminological growth. Amsterdam/Philadelphia, Benjamins.

Langacker, R.W. (2000): Grammar and Conceptualization. Berlín/N.York, Mouton de Gruyter.

Lorente, M. (2002): "Terminología y fraseología especializada". En Guerrero Ramos, G. y M. F. Pérez Lagos (coord.) (2002), págs. 159-179.

Maceiras Fafián, M. (2002): Metamorfosis del lenguaje. Madrid, Síntesis. 
Marías, J. (1973): Antropología metafisica. Madrid, Revista de Occidente (col. El Alción).

Marquant, H. (2002): “'Jerga informática' y calco semántico”. En Guerrero Ramos, G. y M. F. Pérez Lagos (coord.) (2002), págs. 181-195.

Martín-Municio, Á. (1992): "La metáfora en el lenguaje científico", Boletín de la Real Academia Española, LXXII, págs. 221-249.

Martí Sánchez, M. (2003): "Fenomenología y Hjelmslev (encuentros y desencuentros)”. En Muñoz Núñez, $\mathrm{M}^{\mathrm{a}} \mathrm{D}$. et al (eds.): IV Congreso de Lingüística General. IV (Comunicaciones). Universidad de Cádiz/ Universidad de Alcalá, Cádiz, págs. 1727-1738.

Martí Sánchez, M. (2004): "Bases y perfil de la categorización juridica”, Derecho y Opinión, 10.

Martí Sánchez, M. (en prensa): "Indagaciones sobre la lengua del Derecho (El léxico jurídico y sus circunstancias)", Revista Juridica de Castilla-La Mancha.

Martínez-Dueñas, J. L. (1993): La metáfora, Barcelona, Octaedro.

Martínez García, J. I. (1999): “Los derechos humanos y el poder del lenguaje”. Derechos y Libertades. Revista del Instituto Bartolomé de las Casas, 7, págs. 335-357.

Medin, D. L. y Aguilar, C. (2002[1999]): “Categorización”. En R.A. Wilson y F.C. Keil (eds.) (2002 [1999]), Síntesis, págs. 295-298.

Miguel, E. de (2000): "El texto jurídico-administrativo: análisis de una Orden Ministerial". Revista de Lengua y Literatura Españolas, 2, págs. 6-31.

Ministerio de Administraciones Públicas (1991): Manual de estilo del lenguaje administrativo. Madrid, MAP.

Moreso, J. J. (1996): “Lenguaje jurídico". En Garzón Valdés, E. y F.J. Laporta (eds.) (1996),105116.

Muguerza, J. (1992): "Las voces éticas del silencio". En Castilla del Pino, C. (comp.). El silencio. Madrid, Alianza ed., págs. 125-163.

Nuopponen, A. (2002): "Vocabularies for specific purposes: An overview". En Cruse, Hundnurscher, Job y Lutzeier (eds.). Lexicologie/ Lexicology... An International Handbook on the Nature and Structure of Words and Vocabularies. Berlin, De Gruyter, págs. 856-866.

Ortiz Sánchez, M. y V. Pérez Pino (2004[2002]): Léxico juridico para estudiantes. Madrid, Tecnos.

Palmer, G. B. (2000[1996]): Lingüistica cultural. Versión de E. Bernárdez. Madrid, Alianza Ed. (Filología y Lingüística).

Olivercrona, K. (1992[1962]): Lenguaje Juridico y Realidad. México, Fontamara.

Pavel, S. y D. Nolet (2002): Manual de terminología. Trad. esp. de B. de la Vega con la colaboración de G. González y Y. Bernard. Montreal, Ministerio de Obras Públicas y Servicios Gubernamentales de Canadá.

Peralta, R. (1994): La interpretación del ordenamiento jurídico conforme a la norma fundamental del Estado. Madrid, Universidad Complutense de Madrid.

Piaget, J. (1967): Biologie et conaissance. Paris: Gallimard.

Piaget, J. (1978[1975]): La equilibración de las estructuras cognitivas: Problema central del desarrollo. Trad. esp. Madrid, Siglo XXI.

Picht, H. (2002): "La representación de objetos y conceptos". En Guerrero Ramos, G. y M. F. Pérez Lagos (coord.) (2002), págs. 275-305.

Prieto de Pedro, J. (1991): Lenguas, lenguaje y derecho. Madrid, UNED/ Civitas.

Quinn, N. (2002[1999]): "Metáfora y cultura". En R. A. Wilson y F. C. Keil (eds.) (2002[1999]), págs. 819-821.

Roelke, Th. (1999): Fachsprachen. Berlín, Erich Schmidt Verlag.

Ruiz Manero, J. (1996): "Principios jurídicos". En Garzón Valdés, E. y F. J. Laporta (eds.) (1996), págs. 149-159.

Sáez Rueda, L. (2002): El conflicto entre continentales y analíticos. Dos tradiciones filosóficas. Barcelona, Crítica. 
Searle, J. R. (1980[1969]): Actos de habla. Traducción española. Madrid, Cátedra.

Searle, J. R. (2000[1997]): El misterio de la conciencia. Intercambios con Daniel C. Dennet y David J. Chalmers. Trad. esp. Barcelona, Paidós.

Silva, J. Aguiar e. (2001): A prática judiciária entre Direito e Literatura. Porto, Almedina.

Spilner, B. (1992): "Textes médicaux français et allemands". Langages, 105.

Swiggers, P. (1999): "Pour une systématique de la terminologie linguistique: Considérations historiographiques, méthodologiques et épistémologiques". En La terminologie linguistique (Mémoires de la Societé de Linguistique de Paris VI). Lovaina, Peeters, págs. 11-49.

Talmy, L. (2000): Toward a Cognitive Semantics, II (Typology and Process in Concept Structuring). Cambridge, Mass., The MIT Press.

Teso, E. del. (2002): Compendio y ejercicios de semántica I. Madrid, Arco/Libros (Cuadernos de Lengua Española, 74).

Trabant, J. (1992): Humboldt ou le sens du langage. Liège, Mardaga.

Urban, W.M. (1979[1939]): Lenguaje y realidad. México, Fondo de Cultura Económica.

Vernengo, R.J. (1996): "Interpretación del Derecho". En Garzón Valdés, E. y F.J. Laporta (eds.) (1996), págs. 239-265.

Wilson, R.A. y F.C. Keil (eds.) (2002[1999]): Enciclopedia MIT de ciencias cognitivas. I y II. Supervisión científica y coordinación general de la edición española José E. García-Albea. Madrid, Sintesis. 